\title{
ALIMENTOS TRANSGÊNICOS: SEGURANÇA, RISCOS ALIMENTARES E REGULAMENTAÇÕES
}

\author{
CELLI RODRIGUES MUNIZ * \\ CLAISA ANDRÉA SILVA DE FREITAS ** \\ WILMA FÉLIX CAMPÊLO ** \\ GERALDO ARRAES MAIA *** \\ ISABELLA MONTENEGRO BRASIL ${ }^{* \star \star *}$
}

\begin{abstract}
A presente revisão de literatura aborda o tema alimentos transgênicos, enfocando aspectos de segurança e riscos potenciais ao consumidor, bem como questões de rotulagem e regulamentações nacionais e internacionais. Os principais alimentos de origem vegetal e animal transgênicos no mundo foram apresentados, assim como as modificações e vantagens decorrentes de suas transformações. São descritos os mecanismos de surgimento de riscos nesses organismos e os procedimentos de avaliação mundialmente adotados. Os parâmetros de alergenicidade, toxicidade, surgimento de patógenos alimentares resistentes e alteração na qualidade nutricional dos alimentos são destacados pela sua importância em relação à segurança desses alimentos. A tecnologia do DNA recombinante, associada a outras técnicas convencionais de melhoramento e manejo, apresenta enorme potencial para aumentar a produtividade agrícola, beneficiar o meio ambiente e melhorar a qualidade dos alimentos. No entanto, a inocuidade sob o ponto de vista toxicológico e nutricional deve ser igualmente almejada durante o desenvolvimento de alimentos geneticamente modificados, levando-se em conta, acima de tudo, a segurança final do consumidor.
\end{abstract}

PALAVRAS-CHAVE: ORGANISMOS GENETICAMENTE MODIFICADOS; SAÚDE; NUTRIÇÃO; BIOTECNOLOGIA.

* Bióloga, Técnico de Nível Superior II, Embrapa Agroindústria Tropical, FortalezaCE (celli@cnpat.embrapa.br).

** Mestrandas em Tecnologia de Alimentos, Departamento de Tecnologia de Alimentos, Universidade Federal do Ceará, Fortaleza, CE.

*** Ph.D, Professor Titular, Departamento de Tecnologia de Alimentos, Universidade Federal do Ceará, Fortaleza, CE.

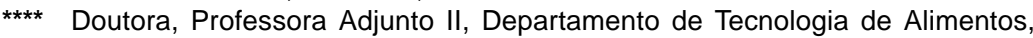
Universidade Federal do Ceará, Fortaleza, CE. 


\section{INTRODUÇÃO}

A União das Nações Unidas projetou que a população mundial em 2050 será de 9,3 bilhões, com incremento de cerca de $35 \%$ da população atual. O mundo deverá produzir $50 \%$ a mais de alimentos para alimentar essa população, preservando a biodiversidade e sem devastar ecossistemas (FAO/WHO, 2003b). O melhoramento de plantas e animais na busca pelo aumento da qualidade e quantidade de alimentos talvez constitua uma das soluções ao problema de suprimento alimentar.

O melhoramento genético clássico de plantas tem sido usado, com sucesso, há muitos anos no intuito de desenvolver espécies com características agronômicas ou nutricionais importantes. No entanto, sempre existiram limitações, que foram superadas pela tecnologia do DNA recombinante. Essa nova tecnologia trouxe ganhos genéticos substanciais ao melhoramento de plantas, que não seriam possíveis com técnicas de melhoramento tradicionais (HERRERA-ESTRELA, 2000). São citadas como características importantes a resistência a pestes, doenças, herbicidas e estresses ambientais, melhoramento de estocagem pós-colheita, melhoria nas características de sabor, aroma e cor dos alimentos, bem como aumento no valor nutricional (CONNER e JACOBS, 1999).

A existência de riscos associados aos organismos geneticamente modificados (OGM) tem sido questionada há mais de vinte anos, muito antes de qualquer produto transgênico chegar ao mercado, gerando grandes discussões que envolveram governos, agricultores, comerciantes, associações de defesa dos animais, entre outros (CAVALLI, 2001).

Segundo a ABRABI (2003) alimentos transgênicos são os obtidos a partir de variedades transgênicas ou que no seu processamento sejam utilizados microrganismos geneticamente modificados.

O presente trabalho versa sobre o tema alimentos transgênicos, enfocando aspectos de segurança e riscos potenciais ao consumidor, bem como questões de rotulagem e regulamentações no Brasil e no mundo. 


\section{CULTURAS GENETICAMENTE MODIFICADAS}

A área global estimada de plantas geneticamente modificadas (GM) é de aproximadamente 44,2 milhões de hectares (JAMES, 2000). As maiores culturas são as de soja, milho e algodão, perfazendo $85 \%$ da área total de transgênicos. O Quadro 1 mostra as principais culturas com as características adquiridas pela inserção de DNA exógeno.

\section{QUADRO 1- PRINCIPAIS CULTURAS GENETICAMENTE MODIFICADAS NO MUNDO E SEUS RESPECTIVOS MELHORAMENTOS}

\begin{tabular}{|c|c|}
\hline Culturas & Melhoramentos \\
\hline \multirow{3}{*}{ Arroz } & Toler ncia salinidade e escassez de Argua \\
\hline & ResistChcia a pragas \\
\hline & Melhoria nutricional (aumento no teor de ferro) \\
\hline \multirow{2}{*}{ Trigo } & Aumento na produ a o adapta 0 \\
\hline & ResistCfncia a pragas \\
\hline \multirow{2}{*}{ Milho } & Aumento na produ ${ }^{a}$ o e adapta ${ }^{a}$ \\
\hline & ResistCrncia a pragas \\
\hline \multirow{3}{*}{ Sorgo } & Toler ncia escassez de Agua \\
\hline & $\begin{array}{l}\text { Resistente a herbicidas e dotado de } \\
\text { propriedades que auxiliam na preven a o de } \\
\text { doen as cardiovasculares }\end{array}$ \\
\hline & Aumento no teor de leo \\
\hline \multirow[b]{2}{*}{$A^{\prime g} \operatorname{dd}^{a} 0$} & ResistCfrcia a pragas \\
\hline & $\begin{array}{c}\text { Aumento na produ a o na qualidade da fibra e } \\
\text { teor de leo }\end{array}$ \\
\hline Batata & $\begin{array}{c}\text { Mais resistente a pragas e s varia I es } \\
\text { climfticas }\end{array}$ \\
\hline Cana-de-a œar & Maturidade precoce \\
\hline Feija 0 & $\begin{array}{c}\text { Resistente ao mosaico dourado, principal v rus } \\
\text { que ataca a planta } 0\end{array}$ \\
\hline $\mathrm{Mel}^{\mathrm{a}} \mathrm{o}$ & Maior durabilidade \\
\hline Mamº & $\begin{array}{l}\text { Resistente mancha anelar, doen a que afeta a } \\
\text { fruta, reduzindo a sua produtividade }\end{array}$ \\
\hline Tomate & $\begin{array}{c}\text { Com sabor e cor mais acentuados, alØm de } \\
\text { maior durabilidade }\end{array}$ \\
\hline
\end{tabular}

Fonte: SHARMA et al., 2002.

Alface com vacina contra a leishmaniose, frutas e hortaliças mais ricas em vitaminas e soja que produz insulina ou hormônio do crescimento estão sendo desenvolvidas no Brasil (CTNBio, 2003). 
A maior parte das culturas disponíveis no mercado foi modificada com o intuito de incorporar novas qualidades sob o ponto de vista agronômico. Essas culturas contam com um ou dois genes externos, codificando proteínas que são expressas em pequenas quantidades e conferindo características como:

$>$ resistência a herbicidas, tornando-as capazes de sustentar aplicações de herbicidas em suas folhas, ao contrário das ervas que perecem mediante tais aplicações;

$>$ resistência aos insetos pela introdução de proteínas inseticidas bacterianas, tais como a toxina $\mathrm{Bt}$;

$>$ esterilidade masculina, facilitando o cruzamento híbrido;

$>$ introdução de fatores abióticos antiestresse, favorecendo a tolerância à salinidade, solos com muito alumínio, etc;

$>$ aumento do metabolismo de amido e outros açúcares;

$>$ alteração da senescência;

$>$ incorporação de fatores nutricionais, como a manipulação genética de carotenóides (SHARMA et al., 2002; AUMAITRE et al., 2002).

Diversas tecnologias têm sido desenvolvidas para a inserção de DNA exógenos no genoma de plantas por meio da engenharia genética. A estratégia para alcançar os objetivos citados acima consiste em acoplar à seqüência de DNA que codifica a proteína de interesse (região codificadora do gene) seqüências de DNA (seqüências reguladoras de expressão gênica, promotor), que contêm sinais responsáveis em dirigir altos níveis de produção da proteína no local desejado.

O DNA exógeno é comumente introduzido por dois métodos. No primeiro, plasmídeos da bactéria Agrobacterium tumefaciens contendo o gene de interesse são integrados ao genoma da planta. No segundo método, biolístico, o DNA é introduzido pelo bombardeamento de partículas de DNA metalizadas (eletroporação de protoplastos). Nas duas técnicas, as células ou tecidos de plantas são cultivados in vitro e regeneradas em plantas inteiras (WATSON et al., 1992a).

\section{ANIMAIS GENETICAMENTE MODIFICADOS}

Muitos dos animais geneticamente modificados (GM) com propósitos alimentícios têm sido transformados com genes relacionados ao crescimento (tais como, hormônio de crescimento somatotropina, 
hormônio do fator de liberação, fator de crescimento insulínico, principalmente em bovinos). No caso de peixes, além dessas características, podem ser citadas a tolerância ao frio, resistência a doenças e esterilidade (MACLEAN, 2003). Além disso, suínos, bovinos e caprinos GM têm sido criados com novas enzimas em seu epitélio intestinal para aumentar a eficiência na utilização de ração. Como exemplos, citam-se os animais que expressam a fitase para aumentar a absorção de fósforo ou enzimas que catalisam a síntese da cisteína (KLETER e KUIPER, 2002).

Um método comum de modificação genética em animais é a microinjeção do DNA exógeno no pronúcleo do zigoto em mamíferos ou no citoplasma do zigoto em peixes. Outra técnica envolve a modificação genética de células maduras seguida da transferência de núcleo para o zigoto (WATSON et al., 1992b).

As principais modificações esperadas pela inserção de genes em animais encontram-se sumarizadas no Quadro 2.

\section{QUADRO 2-GENES PARA ALTERAR GENETICAMENTE ALIMENTOS DE ORIGEM ANIMAL}

\begin{tabular}{|c|c|}
\hline $\begin{array}{c}\text { Fun }{ }^{\text {a }} \text { o biol gica do gene } \\
\text { inserido }\end{array}$ & Vantagens esperadas \\
\hline ResistCrecia a doen as & 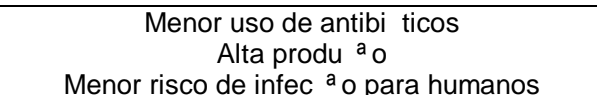 \\
\hline Digest ${ }^{\mathrm{a}}$ o e metabolismo & 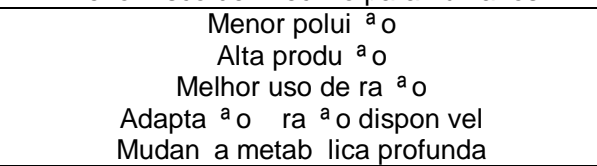 \\
\hline Composi $\stackrel{\text { a }}{o}$ do leite & $\begin{array}{c}\text { Alergenicidade e intoler ncia reduzidas } \\
\text { Composi a o protØca otimizada } \\
\text { Composi a o lip dica otimizada } \\
\text { Prote a o contra doen as (imuniza । es ativas e } \\
\text { passivas) } \\
\text { Teor nutracCEtico incorporado }\end{array}$ \\
\hline Produ $\stackrel{a}{a}$ o de la & $\begin{array}{l}\text { Crescimento de la incorporado } \\
\text { Composi } \stackrel{a}{a} \text { o da la otimizada }\end{array}$ \\
\hline Crescimento da carca a & $\begin{array}{l}\text { Maior desenvolvimento muscular } \\
\text { Menor estocagem de lip dios } \\
\text { Melhor composi } \stackrel{a}{a} \text { o lip dica } \\
\text { Menor composi } \stackrel{a}{\circ} \text { de ra }{ }^{a} 0\end{array}$ \\
\hline Reprodu $\stackrel{\mathrm{a}}{0}$ & Alta prolifera $\stackrel{a}{0}$ \\
\hline
\end{tabular}

Fonte: HOUDEBINE, 2002. 


\section{CONSIDERAÇÕES SOBRE OS RISCOS E AVALIAÇÃO DA SEGURANÇADE ALIMENTOS GENETICAMENTEMODIFICADOS (AGM)}

\subsection{RISCOS ORIUNDOS DO CONSUMO DE ALIMENTOS GENETICAMENTE MODIFICADOS}

Segundo LAJOLO e NUTTI (2003), os perigos potenciais dos AGM podem estar associados ao novo DNA introduzido, aos produtos de expressão desse gene (proteína) e/ou a efeitos não-intencionais decorrentes da introdução no genoma e da expressão desse novo gene.

Em termos gerais, os mecanismos pelos quais os riscos podem surgir em OGM enquadram-se em três categorias:

> expressão de produtos dos genes inseridos;

$>$ alteração do fluxo de vias bioquímicas, resultando na produção de metabólitos secundários indesejados;

$>$ mutagênese pela inserção do novo gene.

Apesar de ocorrerem em baixa freqüência, a avaliação da seguridade dos AGM é extremamente importante nos países que adotam o consumo de tais alimentos (CONNER e JACOBS, 1999).

\subsection{AVALIAÇÃO DE RISCOS DE ALIMENTOS GENETICAMENTE MODIFICADOS}

De acordo com a CTNBio (2003) são exigidos requisitos para estabelecer a segurança dos AGM e de qualquer outro alimento novo produzido por outra tecnologia (que não necessariamente a Engenharia Genética), incluindo a análise de possíveis metabólitos resultantes da sua degradação ou ação. Dentre esses requisitos são avaliados especialmente:

- o potencial alergênico da nova proteína expressa;

- a termoestabilidade e a digestibilidade no meio gástrico ou intestinal;

- a análise bioquímica de taxas de glicosilação e a análise de 
seqüências de aminoácidos da nova proteína em comparação com a de alergênicos convencionais;

- a toxicidade da proteína expressa pelo gene introduzido ou metabólicos de sua ação;

- os efeitos secundários da inserção do gene, como, por exemplo, codificação de enzima indutora de depleção de substrato enzimático;

- o risco teórico de mutagênese pela inserção do gene com alteração da expressão habitual de outros genes;

- a ativação de genes silenciosos ou pouco expressos, provocando biossíntese de metabólicos tóxicos.

\subsubsection{Alergenicidade}

A alergenicidade constitui risco muito importante a ser avaliado, levandose em conta que os alergênicos alimentares são proteínas que podem ser oriundas de genes endógenos ou exógenos. Uma árvore de decisão foi idealizada pela Food and Agriculture Organization (FAO) com o objetivo de avaliar o potencial de alergenicidade de proteínas transgênicas (FAO/WHO, 2003a). O primeiro passo refere-se à comparação da estrutura da nova proteína com estruturas de conhecidos alergênicos pelo alinhamento das seqüências de aminoácidos em bases de dados computacionais. A direção a seguir, após o primeiro passo, depende da fonte do gene. Se a fonte do gene for de alergênico conhecido, a sua reação com soro de pacientes alérgicos a essa fonte deve ser testada. No caso de resultado negativo, testes posteriores devem ser realizados envolvendo soro de pacientes alérgicos a organismos fortemente relacionados à fonte do gene. Dependendo do resultado, novos testes são requeridos envolvendo a digestão in vitro com pepsina e triagens em animais. Se em qualquer dos passos houver resultado positivo, o organismo GM é considerado como provável alergênico (COCKBURN, 2002).

\subsubsection{Toxicidade}

O novo gene pode produzir tanto o efeito desejado como desencadear reação indesejável. Alguns genes de toxinas naturais, tais como inibidores de proteases nas leguminosas cianogênicas (como na 
mandioca e outras), poderiam ser induzidos à expressão e representar risco aos consumidores desses alimentos (UZOGARA, 2000). LAJOLO e NUTTI (2003) afirmaram que proteínas expressas como conseqüência da modificação genética, em produtos apresentados para comercialização, não evidenciaram efeitos adversos relevantes em ensaios químicos e toxicológicos. Além disso, em sua maioria, não se mostraram potencialmente alergênicos.

\subsubsection{Surgimento de patógenos alimentares resistentes a antibióticos}

Genes com resistência aos antibióticos são empregados como marcadores no desenvolvimento e seleção de plantas GM. Esses genes podem ser transferidos para microrganismos residentes no trato gastrointestinal de humanos e/ou animais ao consumirem tais alimentos, gerando patógenos alimentares resistentes aos antibióticos. As agências de vigilância governamentais devem regulamentar o uso desses genes de resistência durante o desenvolvimento de AGM, cujo antibiótico-alvo não deve apresentar importância clínica (UZOGARA, 2000).

\subsubsection{Alteração na qualidade nutricional de alimentos}

Em ensaios realizados com diversos tipos de animais, a composição química dos macro e micronutrientes e de outros fatores antinutrientes de ampla variedade de AGM não evidenciaram alterações relevantes em seu valor nutricional (LAJOLO e NUTTI, 2003).

\subsubsection{Princípio da equivalência substancial (ES)}

Em 1993, a Organização for Economic Cooperation and Development (OECD) formulou o conceito de equivalência substancial (ES) como ferramenta guia na avaliação de segurança de alimentos geneticamente modificados. O Conceito de ES partiu da idéia de que alimentos já existentes podem servir como base para a comparação do alimento geneticamente modificado com o análogo convencional. 
Críticas levantadas, ao longo do tempo, levaram a revisão das bases científicas da aplicação e limitações do conceito de ES. Tal fato resultou em recomendações sobre seus limites e aplicação, bem como sobre a avaliação dos efeitos em longo prazo (alergenicidade e genes marcadores). Também foi recomendado (FAO/WHO, 2003a) o refinamento metodológico para superar algumas limitações da ES, especialmente para futuros produtos mais complexos, estimulando pesquisas sobre o tema. A discussão sobre as limitações do uso prático da ES mostrou a importância da uniformização do conceito nos diversos países (estabelecer etapas e parâmetros de avaliação bem-definidos, com padronização de metodologias para experiências de campo, para análises e estatística) e do desenvolvimento de bases de dados agronômicos e da composição de plantas que permitissem comparações seguras. A questão da padronização foi discutida no âmbito do Codex Alimentarius, que recentemente aprovou a primeira proposta de norma, definindo conceitos básicos e apresentando parâmetros detalhados para a avaliação de segurança dos AGM.

A ES (baseada na composição química dos AGM) não representa aval de segurança, mas auxilia na identificação de semelhanças e diferenças entre os alimentos convencionais e modificados que orientam a necessidade e o tipo de avaliação nutricional e toxicológica a serem adotadas (LAJOLO e NUTTI, 2003).

Os protocolos para avaliação de segurança (caráter científico) envolvem diversas etapas comuns, bem como estratégias específicas para cada caso, sendo baseados na:

- descrição da planta transformada e finalidade da transformação, incluindo aspectos agronômicos, histórico do uso, informações sobre toxicidade e alergenicidade;

- segurança do organismo que originou o gene (eventual patogenicidade, produção de toxinas ou alergenos);

- descrição e caracterização da modificação genética;

- descrição dos vetores e técnicas usadas, caracterização molecular do DNA introduzido e do resultado da transformação (estabilidade genética);

- caracterização dos novos produtos de expressão (bioquímica, funcional e toxicologica). A análise da proteína expressa compreende a metodologia de sua obtenção, sua caracterização 
molecular e funcional (ação bioquímica), sua estabilidade em face do processamento e da digestão. Seguem ensaios toxicológicos em animais e de alergenicidade do produto ou componente, conforme a necessidade de cada caso;

- composição química do produto e análise da equivalência substancial (ES). Envolve macro e micronutrientes, substâncias antinutricionais ou tóxicas, "compostos bioativos" e a busca de eventuais efeitos não-intencionais;

- $\quad$ avaliação de resultados de estudos com animais, conduzidos para verificar mudanças no valor nutricional ou para observação toxicológica;

- $\quad$ avaliação do perigo potencial relativo à alergenicidade com base nas características químicas da proteína expressa, ensaios in vitro ou em animais e humanos.

\section{ROTULAGEM}

A rotulagem de alimentos GM constitui questão delicada que envolve distintos interesses de várias corporações. Os AGM, antes de serem rotulados como tal, devem ser detectados e distinguidos de alimentos autênticos ou genuínos mediante métodos analíticos (LÜTHY, 1999).

Os países que se opõem à rotulagem consideram os seguintes aspectos: estigmatização dos AGM, alarme excessivo dos consumidores, afastamento de negociadores, a rotulagem teria que se estender por toda a cadeia alimentar, gerando problema logístico e aumento nos custos que seriam repassados aos consumidores. Por outro lado, a rotulagem permite a escolha ou abstenção do uso desses produtos pelos consumidores e aos produtores a oportunidade de informar sobre a vantagem adquirida com a modificação (MOSES, 1999).

O Parlamento Europeu aprovou, em julho de 2003, as novas normas para rotulagem de produtos GM. De acordo com a nova legislação, todos os produtos e ingredientes transgênicos deverão ser rotulados incluindo ração animal e alimentos processados. No entanto, ficarão dispensados da rotulagem grãos que contenham até $0,9 \%$ de variedades transgênicas (EUROPA..., 2003). 
No Brasil, o Decreto n. 3.871 (de julho de 2003) determina que: alimentos embalados, destinados ao consumo humano, que contenham ou sejam produzidos com organismos geneticamente modificados, com presença acima do limite de $4 \%$ do produto deverão conter informações a esse respeito em seus rótulos (BRASIL, 2003).

\section{6 ÓRGÃOS REGULATÓRIOS NO MUNDO}

Parâmetros para avaliação da segurança alimentar de AGM têm sido definidos, desde a década de 80, pelos organismos internacionais no âmbito das Nações Unidas, como a OECD, a FAO e a Organização Mundial da Saúde (OMS). O estabelecimento de estratégias para a avaliação da segurança alimentar de produtos advindos da tecnologia de DNA/RNA recombinante, por esses organismos internacionais fundamenta-se no conceito de equivalência. Esse conceito está alicerçado no paradigma de que esses produtos devem apresentar inocuidade, características nutricionais idênticas ao alimento convencional e ausência de efeitos indesejáveis para serem autorizados para consumo (CTNBio, 2003).

Nos Estados Unidos, três agências federais responsabilizam-se pela regulação de produtos geneticamente modificados. O US Department of Agriculture (USDA), responsável pela garantia de que os novos organismos GM não prejudiquem o meio ambiente, a Environmental Protection Agency (EPA), que avalia a seguridade de alimentos e rações GM e o Food and Drug Administration (FDA), que garante a seguridade desse alimento em relação ao seu equivalente convencional (FAUST, 2002).

A União Européia estabelece normas para os alimentos GM pela implementação de regulamentos do Conselho do Parlamento Europeu (EUROPEAN UNION, 1997).

Padrões internacionais são delineados pelo Codex Alimentarius da FAO/WHO por intermédio do Ad Hoc Intergovernmental Task Force and Foods Derived from Biotechnology (ENDO e BOUTRIF, 2002).

No Brasil, a Lei 8.974/95 estabeleceu a criação da Comissão Técnica Nacional de Biosseguranca (CTNBio) encarregada de baixar instruções 
normativas de biossegurança para utilização de OGM e emitir pareceres técnicos sobre a sua liberação no ambiente em escala experimental ou comercial. Com relação aos procedimentos de inspeção e avaliação, o Brasil segue o modelo americano ao exigir que medidas de avaliação de riscos sejam corretamente conduzidas (ODA e SOARES, 2000). Os AGM, além de sujeitos às Instruções Normativas da CTNBio quanto à avaliação de segurança, são posteriormente avaliados pelos Ministérios da Saúde, Meio Ambiente, Agricultura, Pecuária e Abastecimento para aprovação da sua comercialização.

\section{CONSIDERAÇÕES FINAIS}

A tecnologia do DNA recombinante, associada com outras técnicas convencionais de melhoramento e manejo, apresenta enorme potencial para aumentar a produtividade agrícola, beneficiar o meio ambiente e melhorar a qualidade dos alimentos. No entanto, a inocuidade sob o ponto de vista toxicológico e nutricional deve ser igualmente almejada durante o desenvolvimento de AGM, levando-se em conta, acima de tudo, a segurança final do consumidor.

\section{Abstract}

TRANSGENIC FOODS: SAFETY, DIETARY RISKS AND REGULATIONS

The present literature review approaches the subject of transgenic foods assessing security aspects and potential risks to the consumer, as well as labelling and national and international regulations. The main transgenic foods of vegetal and animal origin in the world are presented, as well as the modifications and advantages of their transformations. The emergent risks mechanisms in this organisms and the globally adopted evaluation procedures are described. The parameters of allergenicity, toxicity and occurrence of resistant food pathogens and alteration in the nutritional food quality are stand out by its importance in relation to the safety of this foods. The recombinant DNA technology, associated to other conventional techniques shows great potential to enhance agriculture productivity, to benefit the environment and to improve food quality. Although, the innocuosity by nutritional and toxicological point of view should also be aimed during the development of genetically modified food, regarding above all the final consumers security.

KEY-WORDS: GENETICALLY MODIFIED ORGANISMS; HEALTH; NUTRITION; BIOTECHNOLOGY. 


\section{REFERÊNCIAS}

1 ABRABI. Associação Brasileira das Empresas de Biotecnologia. Alimentos transgênicos. Disponível em: http://www.abrabi.org.br/alimentos.htm. Acesso em 6 out. 2003.

2 AUMAITRE, A. et al. New feeds from genetically modified plants: substantial equivalence, nutritional equivalence, digestibility, and safety for animals and the food chain. Livestock Production Science, v. 74, p. 223-238, 2002.

BRASIL. PLANALTO. Ministério da Ciência e Tecnologia. Decreto no $\mathbf{3 . 8 7 1}$, de 18 de julho de 2001. Disponível em: <http://www.mct.gov.br/legis/leis/ 10688_2003.htm>. Acesso em: 29 ago. 2003.

CAVALLI, S.B. Segurança alimentar: a abordagem dos alimentos transgênicos. Rev. Nutr., Campinas, v. 14, p. 41-46, 2001.

COCKBURN, A. Assuring the safety of genetically modified (GM) foods: the importance of an holistic, integrative approach. Journal of Biotechnology, v. 98, p. 79-106, 2002.

CONNER, A.J.; JACOBS, J.M.E. Genetic engineering of crops as potential source of genetic hazard in the human diet. Mutation Research, New Zealand, v. 443, p. 223-234, 1999.

7 CTNBio. Comissão Técnica Nacional de Biosseguranca. Disponível em: <http://www.furg.br/furg/admini/cibio/com_nac.htm> Acesso em 06 Out.2003.

ENDO, Y.; BOUTRIF, E. Plant biotechnology and its international regulation FAO's initiative. Livestock Production Science, v. 74, p. 217-222, 2002.

EUROPEAN UNION. Regulation (EC) nำ258/97 of the European Parliament and of the Council of 27 January 1997 concerning novel foods and novel food ingredients. Off. J. Eur. Commun, 1997. Disponível em: <http://europa.eu.int/ eur-lex/en/lif/dat/1997/en_397R0258.htm>. Acesso em: 28 jul. 2003.

10 EUROPA autoriza os transgênicos, com rotulagem. O Estado de São Paulo, São Paulo, 3 de jul., 2003. (Geral, Biotecnologia).

11 FAO/WHO. Codex Ad Hod Task Force on foods derived from biotechnology. Codex Alimentarius Commission, Food and Agriculture Organization of the United Nations. Report of a joint FAO/WHO food standards programme. Rome, 2001. Disponível em: <ftp://ftp.fao.org/codex/alinorm01/al0134al.pdf>. Acesso em: 28 jul. 2003a.

FAO/WHO. Report of a joint FAO/WHO Expert Consultation on foods derived from biotechnology: safety aspects of genetically modified food of plant origin. Genebra, 2000. Disponível em: <http://www.fao.org/es/esn/ gm/biotec-e.htm>. Acesso em: 28 jul. 2003b. 
13 FAUST, M.A. New feeds from genetically modified plants: the US approach to safety for animals and the food chain. Livestock Production Science, $v$. 74, p. 239-254, 2002.

14 HERRERA-ESTRELLA, L.R. Genetically modified crops and developing countries. Plant Physiology, v. 124, p. 923-925, Nov. 2000.

15 HOUDEBINE, L.M. Transgenesis to improve animal production. Livestock Production Science, v. 74, p. 255-268, 2002.

16 JAMES, C. Global status of commercialized transgenic crops: 2000. ISAAA Briefs, New York, n. 21. 2000. Disponível em: <http://www.isaaa.org/ publications/briefs/Briefs_21.htm>. Acesso em: 28 jul. 2003.

17 KLETER, G.A.; KUIPER, H.A. Considerations for the assessment of the safety of genetically modified animals used for human food or animal feed. Livestock Production Science, v. 74, p. 275-285, 2002.

18 LAJOLO, F.M.; NUTTI, M.R. Transgênicos: bases científicas da sua segurança. São Paulo: SBAN, 2003. 110 p.

19 LÜTHY, J. Detection strategies for food authenticity and genetically modified foods. Food Control, v. 10, p. 359-361, 1999.

20 MACLEAN, N. Genetically modified fish and their effects on food quality and human health and nutrition. Trends in Food Science \& Technology, v. 14, n. 5-8, p. 242-252, May/Aug. 2003.

21 MOSES, V. Biotechnology products and European consumers. Biotechnology Advances, v. 17, p. 647-678, 1999.

22 ODA, L.M.; SOARES, B.E.C. Genetically modified foods: economic aspects and public acceptance in Brazil. Tibtech, v. 18, p. 188-190, May 2000.

23 SHARMA, H.C. et al. Applications of biotechnology for crop improvement: prospects and constraints. Plant Science, v. 163, p. 381-395, 2002.

24 UZOGARA, S.G. The impact of genetic modification of human foods in the $21 \mathrm{st}$ century: a review. Biotechnology Advances, v. 18, p. 179-206, 2000.

25 WATSON, J.D. et al. Generation of agriculturally important plants and animals. In: RECOMBINANT DNA. $2^{\text {nd }}$ ed. New York: Scientific American Books, 1992a. cap. 24 , p. 471-484.

26 WATSON, J.D. et al. Transferring genes into mammalian cells. In: RECOMBINANT DNA. $2^{\text {nd }}$ ed. New York: Scientific American Books, 1992b. Cap. 12, p. 213234. 